\title{
Appraisal of animal health constraints along the dairy value chains in Kenya
}

John. A. Kidali. T. Karanja., E.O. Mungube., M.W. Maichomo., J.C. Njanja., J.M. Mugambi., E. Thuranira., F.M. Muriithi., L.W. Wamae., and S.O. Nyamwaro.,

Corresponding Author: John. A. Kidali

Email. kidalijohn@yahoo.com

Kenya Agricultural Livestock Research Organization.

P. o. box 00902-32 Kikuyu .Kenya

Telephone 0722529770

\begin{abstract}
The study was carried out in the Counties of Nairobi, Kiambu, Kericho, Kilifi, and Uasin Gishu. The overall objective of the study was to identify and document constraints that limit effective management of dairy value chains. Identification of the constraints will aid in identifying interventions geared towards boosting dairy productivity and profitability. Primary and secondary data were collected through a stakeholder survey amongst the value chain stage actors that revealed the results as:

Research institutions and vaccine producers experienced constraints at institutional levels that impacted on the effective animal health management.

Agro-vets were critical contact points for the actors of the livestock industry and hence possess potential avenues for dissemination of animal health information messages. Some of the Agro-vets were manned by non-professionals, lacked proper storage facilities for the drugs, illegal substandard drugs, and limited input capital and high interest rates on loans thus affecting their operating capacity.

The three Regional Veterinary Investigation Laboratories (VILs) visited served 33 counties. Counties close to VILs presented more samples for testing than those far placed. The total samples recorded were 45,040 comprised of 6,971 in Eldoret, 11,975 in Kericho and 26,091 in Mariakani in a period of 11 years. Ten priority diseases diagnosed accounted for over $85 \%$ of the total. Overall mastitis was the most important at $41.9 \%$, followed by ECF at $10.6 \%$ and nematodes at $4.5 \%$.
\end{abstract}

Keywords: Dairy cattle actors, Constraints, and coping strategy

\section{Introduction}

The dairy industry supports poverty alleviation through contribution to food and nutrition security (Food Business Africa, 2017). In sub-Saharan Africa, losses emanating from livestock diseases are estimated at US\$2 billion per year, a half attributed to direct losses from mortality and the other half to indirect losses as an effect of reduced growth, infertility and inability to work (De Haan \& Bukure, 1991). These diseases hinder the introduction of exotic dairy cattle with high yielding potential into certain areas. Transmissible diseases results into trade and movement restrictions of the dairy products both locally and externally.

Sustainable control of livestock diseases is hampered mainly by the inability of many countries to maintain effective disease surveillance, poor animal health management (Odero-Waitituh, 2017; Maingi and Njoroge, 2010) and an inadequate research capacity. Farmers rely more on drug manufacturers and other service providers for information, which is often 'compartmentalized ' because it is given by different service providers dealing with different commodities. Other constraints to small-holder milk production include inadequate quantity and quality of feeds, low 
technical skills on husbandry practices, limited access to veterinary and artificial insemination (AI) services, poor access to credit facilities and poor access to output markets (inadequate processing and informal milk markets) (Muriuki., 2003; Kembe et al., 2008; Omunyin et al., 2014; Kibiego et al., 2015; Mutavi, 2016).

The status of animal health challenges along the dairy value chains is not clearly understood and documented. The limited understanding on how animal health constraints affect the dairy value chains may contribute to patchy and ineffective attempts by research and development (R\&D) agencies in promoting the dairy subsector.

\section{Materials and Methods \\ Study location}

The study was carried out in Kericho, Kilifi, Kiambu, Nairobi and Uasin Gishu counties to assess animal health constraints encountered by animal health actors along the dairy value chains.

\section{Research design}

The inductive study design by (Saunders et al., 2009) was adopted, which aimed at understanding the importance of animal health constraints at different stages of the dairy value chains by interviewing various actors using multiple methods

Primary and secondary data were collected through a stakeholder survey amongst the value chain stage. Semi-structured questionnaires were developed, pre-tested and administered to collect both qualitative and quantitative data from purposively sampled actors. The survey team directly engaged with responsible officers and where applicable the team extensively reviewed diagnostic and other disease reports. Extensive reviews of monthly, quarterly, annual and surveillance disease reports (2007-2017) from the study Counties were undertaken.

Visits to VILs at Eldoret, Mariakani and Kericho were conducted specifically to capture diagnostic reports for the 11 year period from 2007 to 2017.

\section{Data handling and analyses}

Data coding, entry and cleaning were done with IBM SPSS version 20 software. Descriptive statistics, which include frequencies and cross-tabulations were generated using the SPSS. The results of the descriptive statistics were used to characterize the identified animal health constraints and management practices.

\section{Results and Discussion}

Roles of animal health actors along the dairy value chain stage

The stakeholder survey revealed various animal health actors and the various complementary roles. Research institutions developed vaccines and drugs while vaccine producers produced vaccines in large volumes, distributed and marketed the vaccines to middlemen and end users. Research institutions also tested and validated treatment products and formulations developed by animal health pharmaceutical companies.

\section{Constraints experienced by animal health actors along the dairy value chain}

Disaggregation of the animal health constraints along the dairy value chain showed that regulatory and policy institutions, research institutions, vaccine producers and pharmaceutical companies experienced constraints at institutional level. As shown out in Table 1, constraints encountered 
stalled the institutions from operating effectively at maximum capacities, resulting in poor health and reduced productivity of the Kenyan dairy herds.

Table 1: Constraints experienced by animal health actors along the dairy value chain

Value chain actors Constraints encountered at the institutional level

1. Regulation and policy 1. No streamlined livestock identification and traceability system in institutions (DVS and CDVS) the country

2. Lack of central disease surveillance and control command due to devolution of services

3. Limited human, facilities and capital - resources

2. Research institutions a. Limited human resource and aging work force

(KALRO) b. Moderate facilities - financial and capital resources

c. High costs (search and logistics) in finding disease-free cattle for use in the research processes

3. Vaccine producers 1. Lack of a reliable demand projection / forecast for seasonal (KEVEVAPI) vaccine requirements resulting in under or overproduction

2. Unpredictable cost of inputs which are mainly imported hence affected by inflation

3. High overhead costs due to storage (cold storage)

4. Animal health a. Limited distribution of products to grassroots areas

pharmaceutical b. Low knowledge levels of farmers' needs

companies (Coopers K c. Competition from counterfeit products in the market

Ltd) $d$. Long and expensive bureaucracy in registration of products

Notes: DVS=Directorate of Veterinary Services, $C D V S=$ County Directorate of Veterinary Service, KALRO=Kenya Agricultural and Livestock Research Organization, KEVAVAPI=Kenya Veterinary Vaccine Production Institute,

\section{Proposed solutions to identified constraints}

Collaboration: Collaboration was cited as a solution, which would result in pooling together of resources and expertise to achieve a common goal, hence maximizing on returns of limited financial and human resources.

Working closely with the national and county government extension staff to project seasonal demand for vaccines, drugs and other dairy inputs users thus avoiding overproduction and underproduction.

Revolving fund - a revolving fund was cited as a critical solution to financial limitations in vaccine development and production to limit over-reliance on donors to fund vaccine development and production activities. This can be built from the sales and should be supported by a policy.

Establishment and maintenance of healthy dairy herds for research - Establishment and maintenance of a healthy stock at the KALRO to circumvent the high costs incurred in searching for disease-free cattle for research.

Development of effective strategies for disease surveillance and control, livestock identification and traceability.

\section{Agro-vet shops}

Agro-vets provided veterinary inputs including dewormers, acaricides, antibiotics, anti-protozoa drugs, feed supplements, animal feeds, and mineral supplements. They are important contact points for members of the livestock industry and hence potential avenues for dissemination of animal health information messages. 


\section{Constraints experienced in agro vet's operations}

Some of the agro-vet shops are manned by non-professional staff. Such attendants were not well placed to provide the expected inputs regarding animal health. Availability of substandard illegal drugs on the market, such products may lead to development of resistance. Lack of proper storage facilities and open air services for drugs leading to loss of efficacy. Intense competition between legal and illegal agro-vet due to weaknesses in enforcing regulations and laws. The cost of input capital is too high and borrowing attracted high interest rates.

\section{Proposed solutions to identified constraints}

All agro vet shops should be manned at all times by qualified veterinarians, livestock officers or animal health assistants with overall supervision by the veterinarians for required standards animal health inputs. Inspections to be intensified for quality assurance of agro-vet shops. The DVS, the Veterinary Medicines Directorate (VMD) and the pharmaceutical companies should decisively deal with the illegal drugs. The DVS and the VMD take the necessary legal actions and (VMD) to avail a list of registered drugs.

\section{Investigation laboratories}

Regional Veterinary Investigation Laboratories (RVILs) were setup to carry out investigations on samples submitted by stakeholders in the livestock value chain. The total samples recorded from these RVILs were 45,040 comprised of 6,971 in Eldoret, 11,975 in Kericho and 26,091 in Mariakani over a period of 11 years

\section{Priority dairy cattle diseases diagnosed in VILs from 2007 to 2017}

The three veterinary investigation laboratories diagnosed a total of 6,659 cases of disease. Ten priority diseases diagnosed in each VIL were identified and are presented in Table 2 . The ten priority diseases represented a proportion of about $85 \%$ of all the disease cases. Overall, mastitis was the most important at $41.9 \%$, followed by ECF at $10.6 \%$ and nematodes at $4.5 \%$.

Table 2: Priority diseases diagnosed in VILs from 2007 to 2017

\begin{tabular}{lllllllll}
\hline Diseases & \multicolumn{2}{l}{ Eldoret-VIL } & \multicolumn{2}{l}{ Kericho-VIL } & \multicolumn{2}{c}{ Mariakani -VIL } & Total \\
\hline & No & $\%$ & No & $\%$ & No & $\%$ & No & $\%$ \\
\cline { 2 - 9 } Mastitis & 1,326 & 48.9 & 1,339 & 47.6 & 125 & 11 & 2,790 & 41.9 \\
E.C.F & 251 & 9.3 & 294 & 10.4 & 158 & 14 & 703 & 10.6 \\
Flukes & 221 & 8.1 & 36 & 1.3 & - & - & 257 & 3.9 \\
Nematodes & 116 & 4.3 & 135 & 4.8 & 51 & 4.5 & 302 & 4.5 \\
Pneumonia & 90 & 3.3 & 23 & 0.8 & 79 & 7 & 192 & 2.9 \\
Black Quarter & 81 & 3 & - & - & - & - & 81 & 1.2 \\
Anaplasmosis & 64 & 2.4 & 127 & 4.5 & 69 & 6.1 & 260 & 3.9 \\
Bloat & 63 & 2.3 & - & - & - & - & 63 & 0.9 \\
Rabies & 24 & 0.9 & - & - & - & - & 24 & 0.4 \\
Traumatic & 22 & 0.8 & - & - & - & - & 22 & 0.3 \\
reticulopericarditis & & & & & & & 74 & 1.1 \\
Anthrax & - & - & 16 & 0.6 & 58 & 5.1 & 76 & 1 \\
Malnutrition and Starvation & - & - & - & - & 66 & 5.8 & 6.5 \\
Babesiosis & - & - & 33 & 1.2 & - & - & 33 & 0.5
\end{tabular}




\begin{tabular}{lllllllll} 
Brucellosis & - & - & - & - & 99 & 8.7 & 99 & 1.5 \\
RVF & - & - & - & - & 108 & 9.5 & 108 & 1.6 \\
Johne's disease & - & - & 319 & 11.3 & - & - & 319 & 4.8 \\
Trypanosomosis & - & - & - & - & 92 & 8.1 & 92 & 1.4 \\
Paramphistomes & - & - & 204 & 7.2 & - & - & 204 & 3.1 \\
Others & 455 & 16.8 & 288 & 10.2 & 227 & 20.1 & 970 & 14.6 \\
\hline Total & $\mathbf{2 7 1 3}$ & $\mathbf{1 0 0}$ & $\mathbf{2 8 1 4}$ & $\mathbf{1 0 0}$ & $\mathbf{1 1 3 2}$ & $\mathbf{1 0 0}$ & $\mathbf{6 6 5 9}$ & $\mathbf{1 0 0}$ \\
\hline
\end{tabular}

\section{Treatment and control of disease}

Of all mastitis cases reported, $45 \%$ were sensitive to tetracycline of which $18 \%$ was also sensitive to ampicillins. Total ampicillin sensitive proportion was estimated at $25.6 \%$ of which only $7.6 \%$ of the remaining proportion was sensitive to treatment using ampicillins only. The remaining proportion of $47.4 \%$ were sensitive to other drugs such as sulphonamides, macrolides and nitrofurantoin as shown in Figure 1.

Figure 1: Proportional distribution of mastitis treatment regimes

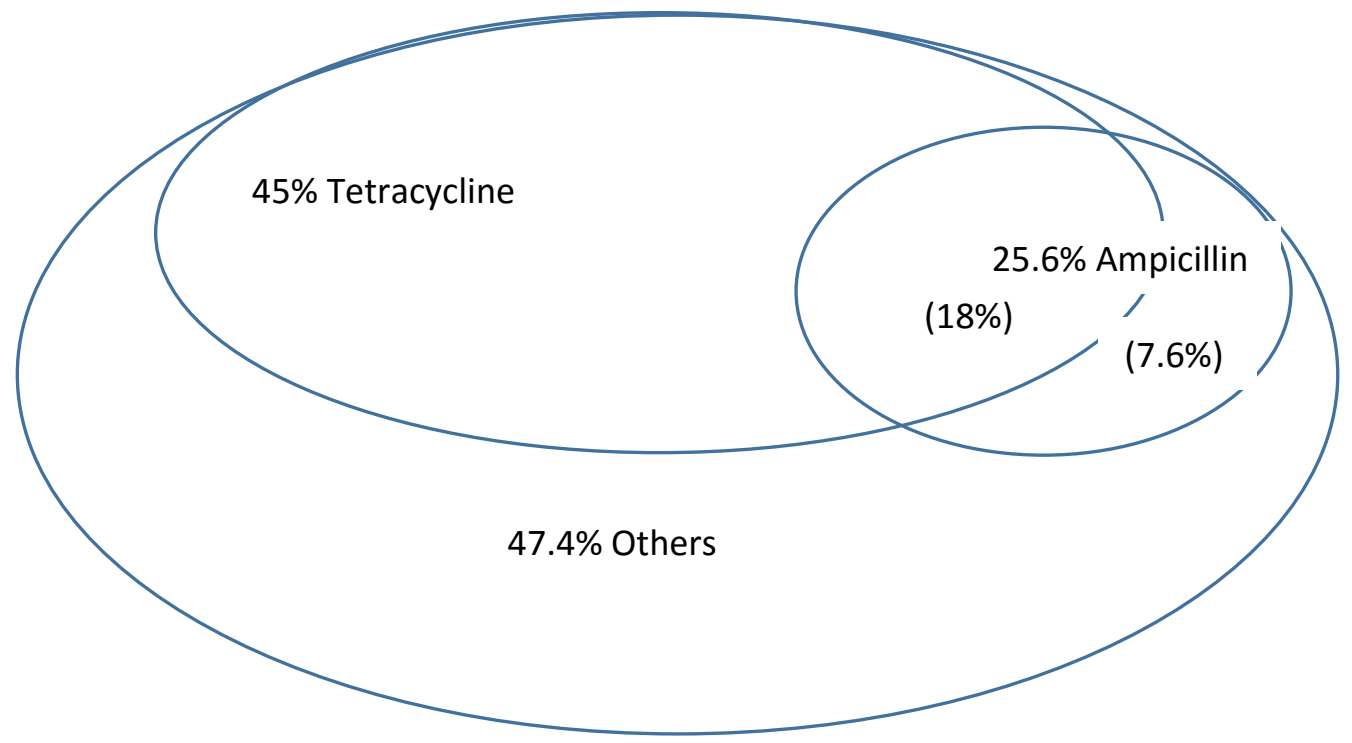

Control of tick-borne diseases was by use of acaricides (dipping, washing). Dewormers were used for treatment of nematodes and flukes. For cases with bacterial and viral infections, clients were advised to use antibacterial and antifungal drugs and where applicable, vaccinations. There was also advice on use of feed and mineral supplements for weak, malnourished and starving animals. 


\section{Major constraints hindering VILS operations}

1. Inadequate budgetary allocation, limiting working in and out of station

2. Few vehicles for on time sample collection led to spoilages

3. Inaccessible laboratory services due to vastness of areas served

4. Few skilled and aging laboratory staff

5. Inadequate capacity for sampling, packaging, storage and transportation of the samples

6. Some obsolete laboratory equipment

7. Delayed and insufficient feedback to clientele after analyses of the samples submitted

8. Lack of a laboratory information system for linking laboratories for sharing information on disease and reporting

\section{Proposed solutions to identified constraints}

1. The national government should increase budgetary allocation to the VILs for them to meet their roles in and out of the stations, vehicle and laboratory equipment purchases.

2. The government should increase the number of satellite stations in far and distant areas.

3. The national government to have a good succession policy of the staff.

4. The VILs to establish efficient information and communication systems for sharing and reporting diseases.

5. The VILs to improve farmers' awareness and technical know-how in preparation of samples to be delivered to laboratories.

\section{Conclusions and Recommendations}

\section{Conclusions}

The study identified key actors and their role along the dairy value chain involved in animal health service provision, policy formulation and implementation. These include: DVS, CDVS, research institutions, drug and vaccine producers and agro-vets.

- Among the actors identified, agro-vet shops were widespread and formed the first contact service provider to dairy farmers, therefore they form the best entry point for enhancing animal health.

- The study identified various policy and institutional factors constraining provision of animal health services along the dairy value chain.

- From regional VIL records, key diseases affecting dairy production were mastitis, ECF and helminthiasis in the three regions.

- Strategies to counter constraints hindering effective provision of animal health services were paramount. To counter the weakening of animal health services caused by decentralization of vet services, the actors suggested strengthening of surveillance and disease control by CDVS.

\section{Recommendations}

From the findings on constraints affecting animal health actors it is recommended that actors should collaborate and network and establish a revolving fund for building animal health capacities. All dairy animal health value chain actors should be involved in participatory processes in determining forward strategies for improving animal health management guidelines on disease control, livestock identification and traceability. The roles of the Agrovets should be strengthened 
to complement government veterinary services, access to loans and business security. Stringent regulations and supervision should be enforced and implemented to allow only qualified operators to conduct good animal health businesses and practices. Agro-vet markets should also be insulated and protected from entry of substandard drugs and materials.

Further recommendations are proposed that actors in the dairy value chains should be facilitated fully in order to exploit the potential in VILs' management of disease investigatory processes. The national government should allocate more funds to VILs to replace all old and outdated laboratory equipment with modern facilities for better performance and multitasking and that the focus should be on priority diseases that include mastitis, ECF and nematodes limiting dairy production.

\section{Acknowledgement}

We are grateful to the KALRO Director General and KALRO management for facilitating the implementation of this study. We highly appreciate the financial support received from USAID through the KALRO-USAID FtF IARD project which enabled us to conduct this study. We also express profound appreciation to the following stakeholders for their support and collaboration in the study: Directorate of Veterinary Services (Drs. H.O. Oyas, Njogu, and R. S. Wangila), County Directors of Veterinary Services in Uasin Gishu, Kericho and Kilifi, Directors of Regional Veterinary Investigation Laboratories (Uasin Gishu, Kericho and Mariakani). The Managing Director of Kenya Veterinary Vaccine Production Institute, Cooper Kenya Ltd and various agrovets we visited in Uasin Gishu, Kericho and Kilifi counties provided valuable information. We are grateful to all the value chain actors along the dairy value chain for their patience in responding to all our questions. We are also thankful to all the enumerators who assisted in data collection and all the KALRO-VSRI staff who provided the necessary support during the activities.

\section{REFERENCE}

De Haan, C. \& Bekure S. 1991. Animal health services in sub-Saharan Africa: Initial experiences with new approaches, ALPAN Network Paper 29, International Livestock Centre for Africa, Addis Ababa.

Food Business Africa (2017).

Kembe, A. M., Odhiambo, M.O., Kibiego, M.B. and Mbondo, P.N. 2008. The Role of Market Access for Smallholder Dairy Farmers in Enhancing Rural Income: Recent experiences from Kisii Central District in Kenya. Paper presented during the $1^{\text {st }}$ National Conference and Exhibition for Research Results Dissemination and Review of Innovations, K.I.C.C, Nairobi.

Kibiego, M.B., Lagat, J.K. and Bebe, B.O. 2014. Competitive of Smallholder Milk Production Systems in Uasin Gishu, Kenya. Journal of Economics and Sustainable Development, 6 (10): 39-45.

Maingi, N. and Njoroge, G. K. 2010. Constraints on production, disease perceptions and ticks and helminths control practices on dairy cattle farms in Nyandarua District, Kenya. Livestock Research for Rural Development. Volume 22, Article \#138. http://www.lrrd.org/lrrd22/8/main22138.htm Last accessed 6th July 2017.

Muriuki, H. 2003. Milk and Dairy Products, Post-harvest Losses and Food Safety in SubSaharan Africa and the Near East. Food and Agriculture Organization Prevention of Food Losses Programme. 
http://www.fao.org/fileadmin/templates/ags/docs/dairy/P1assessmentkenya.pdf, Retrieved March 23, 2017.

Mutavi, S. K., Kanui, T.I., Njarui, D.M., Musimba, N.R. and Amwata, D.A. 2016. Innovativeness and Adaptations: The way forward for Small scale Peri- Urban Dairy Farmers in semi-arid Regions of South Eastern Kenya. International Journal of scientific Research and Innovative Technology, 3 (5): 1-14.

Odero-Waitituh, J.A. 2017. Smallholder dairy production in Kenya; a review. Livestock Research for Rural Development. Volume 29, Article \#139. http://www.lrrd.org/lrrd29/7/atiw29139.htm. Last accessed 6th July, 2017.

Omunyin, M.E., Ruto, J., Yegon, M.K. and Bii, A. 2014. Dairy Production Constraints in Kericho and Bomet Counties of Kenya: Evidence from Farmers Fields. International Journal of Science and Research, 3 (12). 1241-1246.

Saunders, M., Lewis, P., and Thornhill, A. 2009. Research Methods for Business Students, 5th Edition. Harlow, England: FT Prentice Hall-Pearson Education Limited. 